\title{
Dynamic changes in physic-chemical properties and bacterial community during natural fermentation of tomatoes
}

\author{
Xiaoli ZHOU ${ }^{1,2 *}\left(\mathbb{D}\right.$, Qinglin GUAN ${ }^{1}$, Yumeng QIN ${ }^{1}$, Zhicheng QIN ${ }^{1}$, Bin DU ${ }^{1,2}$, Dong LIN $^{1,2}$
}

\begin{abstract}
This study revealed for the first time the dynamic changes of bacterial community and physic-chemical properties in the process of tomatoes fermentation. In the early phase of fermentation, Proteobacteria and Firmicutes account for $86.04 \%$ and $9.97 \%$, respectively. Then, Firmicutes replaced Proteobacteria to be the dominant phylum from day 10. Among then, Lactobacillus decreased from 20 to 30 days and then rapidly increased. The total sugar showed a gradual decreased while the nitrite content increased in the early phases. The total acid content increased from initial $0.6 \%$ to $2.03 \%$ on day 30 , mainly including citric acid, malic acid and lactic acid. In the later stages, the number of microorganisms and bacterial community tended to be stable, along with the content of organic acids and nitrite. During fermentation, the physic-chemical parameters inevitably change, mainly due to microbial metabolism, affecting in turns the development of the micro-ecosystem. These results contribute to our knowledge about bacterial participation in the process of fermentation and will help improve the quality of fermented food and vegetables.
\end{abstract}

Keywords: natural fermentation; bacterial community; Lactobacillus; high-throughput sequencing; physic-chemical properties.

Practical Application: Bacterial Community during natural fermentation of tomatoes.

\section{Introduction}

Vegetables and fruit are basic sources of water-soluble vitamins, vitamin A, phytosterols, dietary fibre, minerals and phytochemicals in a human diet (Di Cagno et al., 2013). Scientific research shows that the consumption of vegetables and fruits can prevent chronic diseases, such as hypertension, obesity and coronary heart disease (He et al., 2007). Therefore, there is an increasing consumer trend towards health-promoting products with high nutritional value and rich flavoured food.

It is well established that diet directly influences the structure and function of our gut microbiome, which in turn, influences one's overall health (David et al., 2014). In recent years, healthy and safe, fruit or vegetables fermented beverages have become more and more favoured by consumers, with the improvement of people's living standards (Dimidi et al., 2019). Fermented food is a functional product made from one or more kinds of fresh vegetables, fruits or mushrooms, fermented by many kinds of beneficial bacteria (Di Cagno et al., 2013; Dimidi et al., 2019; Raghuvanshi et al., 2019); it plays an important role in the human diet and is widely consumed all over the world. Fermented products not only have unique and appealing flavours but also are rich in a large number of vitamins, amino acids, minerals (Di Cagno et al., 2013; Hur et al., 2014), and enzymes, secondary metabolites and other nutrients (Anal, 2019), which can supplement nutrition in the absence of fresh vegetables. The natural fermentation of fruit and vegetables involves Lactobacillus, Leuconostoc and Weissella, which can promote the formation of flavourful substances (Tamang et al., 2016; Hao \& Sun, 2020).
Lactic acid, produced by Lactobacillus, results in the decrease of $\mathrm{pH}$, improving gastrointestinal function, enhancing immunity and has anti-ageing properties (Di Cagno et al., 2013). Generally, fermentation has a positive influence on the total phenolic content and antioxidant activity; however, the degree of influence depends on the species of microorganism (Hur et al., 2014; Jayabalan et al., 2008). Lactic acid bacteria are widely used in food fermentation, and Lactobacillus plantarum among others is the species most frequently used to ferment food products of plant origin (Hur et al., 2014). Through its own material metabolism, microorganisms make fermentation materials produce a lot of complex intermediate metabolism or cross metabolism, realize the metabolic transformation between metabolic substances, and produce new bioactive substances and new biological enzymes. The microbiota responsible for the spontaneous fermentation of raw vegetables and fruit deserves a systematic and in-depth research as tools to improve the microbial safety of fermented foods and promote the scale development of related industries (Anal, 2019; Paramithiotis et al., 2012).

Tomato (Lycopersiconesculentum Mill.) is a semi-erect or trailing herb of the genus Lycopersicon (Solanaceae). Its fruit is rich in nutrients and unique in flavour, which plays an indispensable role in the human diet (Opara et al., 2012; Pellicanò et al., 2020). Tomato is one of the most widely planted vegetable in the world. It has excellent nutritious value, with nutrients such as vitamins, lycopene, flavonoids, polyphenols, and can supplement a variety of vitamins and minerals needed by the human body 
(Alarcón-Flores et al., 2015; Din et al., 2020; Pellicanò et al., 2020). Previous research reported that tomatoes have various potential pharmacological functions, such as improvement of inflammation, prevention of hyperlipidaemia, inhibition of disaccharide activity, and reduction of diabetes risk and prevention of prostate cancer (Alarcón-Flores et al., 2015; Siddiqui et al., 2016). Fermentation, it seems to be an ideal processing step; it increases the level of safety, extends shelf life and improves organoleptic properties. Furthermore, since minimal, if any, thermal processing is involved the phytochemicals are not exposed to detrimental factors that may lead to reduction in their concentration and the healthrelated benefits. On the other hand, the fermented products are considered as a kind of functional food containing functional components derived from tomatoes. Their production process involves various microorganisms which usually determine their quality and flavour (Di Cagno et al., 2013; Aldrete-Tapia et al., 2014; Rezac et al., 2018). Our previous research found that the naturally fermented mature red tomatoes have good antioxidant activity, especially scavenging ABTS and DPPH free radicals; and the total phenol increased and the vitamin c decreased gradually with the extension of fermentation time, the lycopene decreased first and then increased (Zhou et al., 2019). And, spontaneous fermentation of green tomatoes at different stages of ripening revealed a significant effect on the growth kinetics of lactic acid bacteria and the final $\mathrm{pH}$ value (Paramithiotis et al., 2014); however, the study was limited to the analysis of some bacteria at sub-species level by RAPD-PCR and rep-PCR. And due to the influence of climate, human operation and other factors, the quality of fermented tomatoes beverages is difficult to guarantee. It is essential to investigate the microbial community structure to control and improve product quality in broth from naturally fermented tomatoes. In addition, the type and quantity of the organic acids directly affects the taste and quality of the fermented food, and in order to better understand how to optimize the health benefits of fermented food, it is of great significance to monitor the microbial community structure and its changes and the content of organic acids during fermentation for the quality and safety of tomatoes fermentation.

The traditional approach for investigating microbial composition is to isolate microbes using various selective culture media. This culture-dependent method can provide quantitative data for different microbiota and pure culture isolates can be used to study their physiological functions (Połka et al., 2015). However, this method is limited due to the fact that it can only reveal a small proportion of the viable microbes present (Carraro et al., 2011). An alternative is high-throughput sequencing technology, which has been widely used for the classification of microorganisms in fermented foods, such as cheese (Aldrete-Tapia et al., 2014), wine (Berbegal et al., 2019), fermented vegetables and beverages (Ono et al., 2014; Elizaquível et al., 2015). However, until now, this approach has not been applied to research on the microbial community in naturally fermented tomatoes. In the present study, we constructed a high-throughput sequencing library by $16 \mathrm{~S}$ rDNA to identify the bacterial diversity during the fermentation of tomato, and the major physic-chemical properties by chemical analysis, which provided theoretical basis for further elucidating the health function mechanism and comprehensive development of fruit and vegetable fermentation products.

\section{Materials and methods}

\subsection{Tomatoes preparations and sample collection during natural fermentation}

Tomatoes used in this research were collected from Guizhou province, China. The surface of the tomatoes was rinsed with tap water several times to remove the impurities adhering to the tomato surface. The surface was then rinsed with pure water and dried. Tomatoes and sucrose were added into sterilized glass bottles at the ratio of $3: 1(\mathrm{w} / \mathrm{w})$ and placed in a cool and ventilated place. Initial samples were taken from the mixed samples without fermentation at $0 \mathrm{~d}(\mathrm{G} 1)$, and then the solutions were fermented continuously for $90 \mathrm{~d}$ at room temperature $\left(20-25^{\circ} \mathrm{C}\right)$. Further samples were taken from three different positions in the bottles at 10 days, 20 days, 30 days, 60 days and 90 days, labelled as G2, G3, G4, G5 and G6 according to the sampling day, respectively. The samples were stored at $-20{ }^{\circ} \mathrm{C}$ for physic-chemical and microbial diversity analyses.

\subsection{Physic-chemical analysis}

The samples were mashed into homogenized pastes and the total acid and nitrite were assessed according to the method reported by Kang et al. (2019); the standard curve equation of nitrite was $y=0.2487 x+0.0127, R^{2}=0.9937$. The water-soluble carbohydrate was determined using the anthrone method (Murphy, 1958), the standard curve equation of the carbohydrate was $y=1.1753 x-0.0241, R^{2}=0.9944$.

The concentrations of oxalic acid, tartaric acid, malic acid, succinic acid, citric acid, lactic acid and acetic acid were determined by using liquid chromatography (Shimadzu) equipped with a $\mathrm{C}_{18}$ column $(250 \mathrm{~mm} \times 4.6 \mathrm{~mm}, 5 \mu \mathrm{m})$. The mobile phase was $3 \%$ acetonitrile - $97 \% 0.01 \mathrm{~mol} / \mathrm{L} \mathrm{KH}_{2} \mathrm{PO}_{4}$, and the flow rate was $0.8 \mathrm{~mL} / \mathrm{min}$, injection volume was $10 \mu \mathrm{L}$, column temperature was $30^{\circ} \mathrm{C}$ and UV detector wavelength was $210 \mathrm{~nm}$ (Scherer et al., 2012). For HPLC determination, the fermentation broth was centrifuged and filtered through a $0.45 \mu \mathrm{m}$ microporous membrane. The correlation coefficients of the 7 organic acids were all greater than 0.99 (Table 1).

\subsection{DNA extraction}

$2 \mathrm{~mL}$ samples were mixed with $8 \mathrm{~mL} 0.1 \mathrm{~mol} / \mathrm{L}$ Tris- $\mathrm{HCl}$ ( $\mathrm{pH}$ 8.0), shaken well, and filtered through three layers of sterile gauze. The filtrate was centrifuged at $10,000 \times \mathrm{g}$ for $10 \mathrm{~min}$ at $4{ }^{\circ} \mathrm{C}$. The Bacteria DNA Kit (Sangon Biotechnology Co., Ltd, Shanghai,

Table 1. Liner equations for the standard curve of 7 standard organic acid.

\begin{tabular}{lccc}
\hline \multicolumn{1}{c}{ Organic acid } & Liner equations & $\mathrm{R}^{2}$ & $\begin{array}{c}\text { Linear range } \\
(\mathrm{mg} / \mathrm{mL})\end{array}$ \\
\hline Oxalic acid & $\mathrm{y}=9.0 \times 10^{6} \mathrm{x}-55111$ & 0.9994 & $0.05 \sim 0.5$ \\
Tartaric acid & $\mathrm{y}=1.0 \times 10^{6} \mathrm{x}-12462$ & 0.9978 & $0.05 \sim 0.5$ \\
Malic acid & $\mathrm{y}=567053 \mathrm{x}-1308.4$ & 0.9990 & $0.05 \sim 0.5$ \\
Succinic acid & $\mathrm{y}=434590 \mathrm{x}-4374.4$ & 0.9923 & $0.05 \sim 0.5$ \\
Citric acid & $\mathrm{y}=782642 \mathrm{x}-4170.8$ & 0.9999 & $0.05 \sim 0.5$ \\
Lactic acid & $\mathrm{y}=595572 \mathrm{x}-16135$ & 0.9951 & $0.025 \sim 0.25$ \\
Acetic acid & $\mathrm{y}=559372 \mathrm{x}-247.25$ & 0.9996 & $0.05 \sim 0.35$ \\
\hline
\end{tabular}


China) was used to extract total bacterial DNA. The total DNA concentration and quality were checked using a NanoDrop 2000 spectrophotometer and agarose gel electrophoresis.

\subsection{S rDNA gene amplicon sequencing}

From extracted DNA the V4 region of the bacterial $16 \mathrm{~S}$ rDNA was amplified by PCR using the universal bacterial primers with the following reaction conditions: preliminary denaturation at $95^{\circ} \mathrm{C}$ for $5 \mathrm{~min}$; followed by 30 cycles of denaturation at $94^{\circ} \mathrm{C}, 58^{\circ} \mathrm{C}$, and $72^{\circ} \mathrm{C}$ for $1 \mathrm{~min}$; and final extension at $72^{\circ} \mathrm{C}$ for $5 \mathrm{~min}$. Then, the purified PCR products were sequenced with a MiSeq Illumina instrument (Illumina, USA) at Sangon Biotech Co., Ltd (Shanghai, China) (Jung et al., 2014; Połka et al., 2015).

\subsection{Biological information analysis}

Based on the OTU analytical results, Shannon and Chao1 diversity indices were calculated for each sample separately to obtain information on species richness and evenness. Based on taxonomic information, statistical analysis of community structure was carried out at each classification level. Beta diversity of the metabolomics data was calculated using the Bray-Curtis dissimilarity metric and visualised in Principle coordinate analysis space (PCoA) using the EMPeror software (Lozupone et al., 2006; Vázquez-Baeza et al., 2013).

\subsection{Statistical analysis}

All statistical analyses were performed using the SPSS statistics program (Version on 22.0, IBM Co., Somers, NY, USA). The results were subjected to one-way ANOVA analysis, with $p<0.05$ considered as statistically significant. All experiments were repeated three times, data were expressed as mean \pm standard deviation.

\section{Results and discussion}

\subsection{Physic-chemical dynamics during natural fermentation of tomatoes}

The total acid, nitrite, water-soluble carbohydrate and organic acid concentration of tomatoes fermentation showed variation during the different phases of the naturally fermented, as shown in Figure 1.

Total acid content is one of the most important environmental parameters affecting food fermentation. It is closely related to microbial growth and the structural changes in phytochemicals during fermentation (Di Cagno et al., 2013). Our results indicated that the content of total acid increased significantly at first $(p<0.05)$ and then tended to be stable $(p>0.05)$. A slight increase in total acid occurred because of the rich-nutrient environment during the $0-30 \mathrm{~d}$ period, which is conducive to large-scale reproduction of acid-producing microorganisms, resulting in a large number of secondary metabolites such as lactic acid and citric acid (Ruiz-Moyano et al., 2011). Interestingly, total acid content gradually reduced after day 30 . These results are in agreement with observed variation in the microbial community structure, as after day 30 Lactobacillus, which possesses a strong acid-producing ability and acid resistance became a prominent component of the community (Wang et al., 2013): on the one hand, the low $\mathrm{pH}$ may affect the growth, reproduction and metabolism of some microorganisms to prevent contamination of miscellaneous bacteria and food spoilage; on the other hand, the lactic acid fermentation by Lactobacillus changes polybasic acids into monobasic acids in the later stages of fermentation, which will inhibit the increase of total acids.

Carbohydrates are important nutrients for the growth of microorganisms. As the main carbon source in the natural fermentation process, carbohydrate content is one of the core indicators for changes in microbial metabolism during the tomato fermentation process. In Figure 1B, the total sugar content decreased within 20 days, because of the tomato is rich in nutrients and has an environment suitable for the proliferation and growth of microorganisms at the beginning of fermentation; Carbohydrates, as the main component of tomato, were transferred into reducing sugars and organic acids through metabolism by fast-growing microbes. The change in total sugar content was relatively slow until the fermentation reached 30 days. Due to prolonged fermentation, a successive pattern of substrate consumption occurred, i.e., first sucrose, followed by monosaccharides, organic acids, and finally maintained at $20 \%$, which made tomato fermented products have a good taste. Consequently, the fermentation of the tomatoes processes yielded a higher accumulation of microbial metabolites in fermentation, which gave a greater fermentation effect on the fermenting.

Nitrite content is an important index to evaluate the safety of fermented fruit and vegetables. As shown in Figure 1C, the content of nitrite increased rapidly within 20 days fermentation $(p<0.05)$, which may be due to the reduction of nitrate to nitrite by some miscellaneous bacteria, so that the nitrite reached the maximum $(2.9 \mathrm{mg} / \mathrm{kg})$ at this stage, but it was far lower than the limit of $20 \mathrm{mg} / \mathrm{kg}$ for pickled vegetables specified in the "limit of pollutants in food"(GB 2762-2017). In the fermentation process, organic acid has a great influence on the growth of microorganisms and the production of metabolites. In the middle stage of fermentation, the concentration of nitrite decreased with the increase of lactic acid bacteria and the formation of a stable microbial community. These lactic acid bacteria can inhibit harmful microorganisms during fermentation, resulting in a gradual decrease in nitrite content after 20 days of tomatoes fermentation, so as to avoid the damage of nitrite produced by tomato after long-term storage, this is consistent with the results of naturally fermented vegetables (Kang et al., 2019).

Organic acids are natural products of tomatoes, and the type of acid and the quantity strongly affect the flavour of the product. The type and quantity of the organic acid changes during the process of natural fermentation, so organic acid is an important indicator for fermented products (Shukla et al., 2010). Organic acids in microbial fermentation can also help digestion and absorption of food and improve people's appetite. The change of organic acids in naturally fermented tomatoes is shown in Figure 1D. Interestingly, a sharp increase in total lactic acid content was detected in the broth, it increased from an initial $0.02 \mathrm{mg} / \mathrm{mL}$ to $0.30 \mathrm{mg} / \mathrm{mL}$ on day 30 , but then gradually reduced to $0.18 \mathrm{mg} / \mathrm{mL}$ on day 90 . This phenomenon mainly caused by the interaction of various microorganisms during 

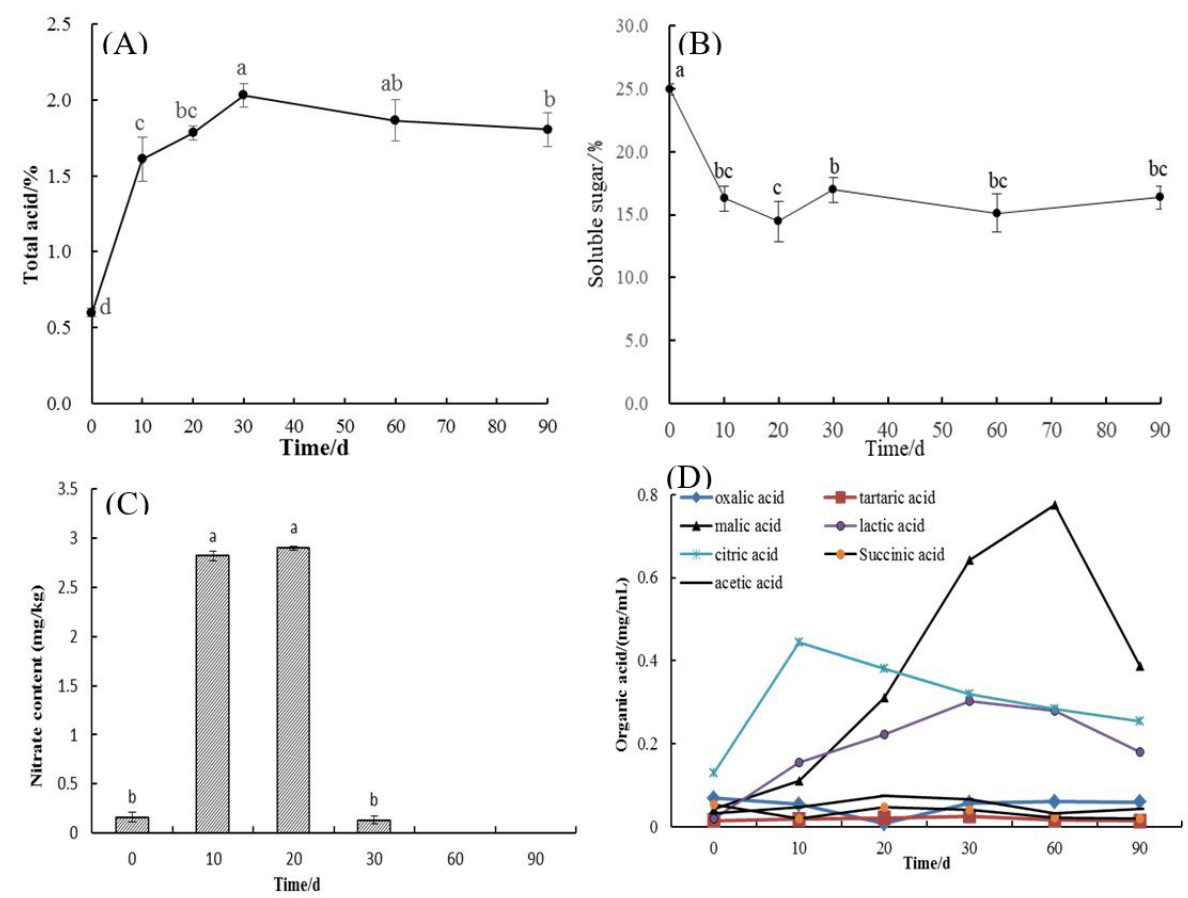

Figure 1. The content of total acid (A), sugar (B), nitrate (C) and organic acid (D) during natural fermentation of tomatoes. Values with no letter in common are significantly different $(\mathrm{p}<0.05)$.

fermentation of tomatoes, which regulated lactic acid and other organic acids of the entire tomato production fermentation phase by turning glucose into organic acid. These results are in agreement with the observed increase in Lactobacillus at day 30, which possesses strong acid-producing ability and acid resistance (Wang et al., 2013). And, the content of malic acid increased from $0.04 \mathrm{mg} / \mathrm{mL}(0 \mathrm{~d})$ to $0.77 \mathrm{mg} / \mathrm{mL}(60 \mathrm{~d})$, the content of citric acid increased from $0.13 \mathrm{mg} / \mathrm{mL}(0 \mathrm{~d})$ to $0.44 \mathrm{mg} / \mathrm{mL}(10 \mathrm{~d})$, respectively; suggesting the environment is rich in nutrients in the early stage of fermentation, which is conducive to the largescale reproduction of some acid-producing microorganisms. Malic acid could be converted into lactic acid through malolactic fermentation, whereas citric acid could be converted into lactic acid and acetic acid, following pyruvate metabolism, or succinic acid through the reductive branch of the tricarboxylic acid cycle (Gänzle, 2015). The consumption of carbohydrates produces citric acid, lactic acid and other metabolites, which increases the total acid content. With the increase of organic acid content in the fermentation broth, the lower $\mathrm{pH}$ led to the inhibition of microbial growth and reproduction, thus reducing the rate of organic acid production. As the carbon source decreased in the later stage of fermentation, this resulted in the consumption and utilisation of some organic acids by microorganisms as alternative carbon sources. The citric acid, malic acid and lactic acid were the main organic acids in the broth of naturally fermented tomatoes. The outcome of spontaneous vegetable fermentations is determined by the interaction of many factors, including the naturally occurring microbial populations in the raw materials and environmental conditions (Paramithiotis et al., 2014). Liu et al. (2006) and Topalovic \& Mikulic-Petkovsek (2010) showed that the main organic acids are tartaric acid, malic acid and citric acid in grapes, and the content of acetic acid, succinic acid and shikimic acid was relatively small, indicating that the differences in the type and quantity of organic acids may be related to various factors such as raw materials, microbial composition, fermentation methods and environment.

\subsection{Microbiome dynamics}

Few studies have been carried out on the microbial community in the fermentation process of tomatoes. So, clarifying the structure of the bacterial community in tomato fermentation is helpful to reduce the potential risk of natural fermentation to human health (Anal, 2019). In the bacterial diversity analysis a total of 16 phyla, 26 classes, 43 orders, 81 families and 129 genera were identified in the process of naturally fermented tomatoes using high-throughput sequencing.

\subsection{Analysis of bacterial abundance and diversity during natural fermentation of tomatoes}

During fermentation, the physic-chemical parameters inevitably change, mainly due to microbial metabolism, affecting in turns the development of the micro-ecosystem.

\section{Alpha diversity index}

Thea-diversity is mainly concerned with the sample diversity analysis, which can reflect the number of species in the microbial communities. The v3-v4 region of the bacterial $16 \mathrm{~S}$ rDNA was sequenced and 440-470 bp high-quality sequences were obtained. Based on a $97 \%$ OTU similarity level, the species richness and diversity of environmental communities can be estimated by the analysis of Chao1, Shannon, Simpson (Table 2). It was found that the dynamic changes in microbial flora during fermentation are complex. The coverage values in all samples ranged from 
Table 2. Sequence abundance and microbial diversity during natural fermentation of tomatoes.

\begin{tabular}{ccccccl}
\hline Group & OTU & $\begin{array}{c}\text { Shannon } \\
\text { index }\end{array}$ & $\begin{array}{c}\text { ACE } \\
\text { index }\end{array}$ & $\begin{array}{c}\text { Chaol } \\
\text { index }\end{array}$ & Coverage & Simpson \\
\hline G1 & 102 & 3.188011 & 155.7111 & 143.0625 & 0.947251 & 0.111198 \\
G2 & 212 & 1.547875 & 739.0882 & 458.453 & 0.996086 & 0.34742 \\
G3 & 811 & 1.591592 & 3163.925 & 1842.481 & 0.989184 & 0.390484 \\
G4 & 429 & 1.629388 & 2454.42 & 1141.486 & 0.992485 & 0.291149 \\
G5 & 1339 & 1.552369 & 3673.394 & 2449.579 & 0.989141 & 0.613565 \\
G6 & 1306 & 0.445646 & 3165.684 & 2385.408 & 0.990039 & 0.918406 \\
\hline
\end{tabular}

G1: sample fermented for 0 day; G2: sample fermented for 10 days; G3: sample fermented for 20 days; G4: sample fermented for 30 days; G5: sample fermented for 60 days; G6: sample fermented for 90 days.

0.947 to 0.996 , suggesting that most of the bacterial communities were detected. The Shannon index shows species diversity in a sample, as well as Simpson index (Hao \& Sun, 2020), them of the six groups were between 0.11 and 3.18 , which were inversely proportional. The values of G1 and G6 were quite different, with G1 having the highest diversity index, indicating that there was a great difference in microbial community in G1 group. The Shannon index decreased significantly after 10 days of fermentation, during the G2-G5 period it was relatively stable, and then it decreased significantly after 60 days, indicating that the richest diversity appeared at G1 and then decreased gradually with the extension of fermentation time. These results were consistent with the results of species distribution heat map analysis. The bacterial diversity exhibited a correlation with fermentation time, and differences in bacterial communities were observed during different fermentation stages.

\section{Beta diversity}

Beta diversity is used to compare the differences in the microbial community composition of different groups, it is the rate of change in species composition along an environmental gradient or between communities. It can be seen from Figure 2A, the six groups of samples divided into two branches. The bacterial community structure was similar among the samples at 10 days, 20 days, 30 days, 60 days and 90 days of fermentation, and these gathered together in the top branch. The bacterial community structure was similar between the samples of 0 -day fermentation, gathering in the bottom branch. The similarity in community structure was particularly high between the samples of 60-day and 90-day fermentation, and between the samples of 10-day, 20-day and 30-day fermentation, which shows that the bacterial community structure of tomato fermentation is different throughout the fermentation process.

\section{OTU venn diagram}

The similarity in composition and overlap of samples can be directly displayed at different classification levels with a Venn diagram. As shown in Figure 2B, 16, 23, 71, 36, 255 and 265 OTUs were generated from G1 to G6 sample, respectively; a total of 38 OTUs were shared by the sample in the six groups, which indicated that these groups had a low level of similarity in bacteria diversity. The non-overlapping part of the venn diagram indicates the unique species in the naturally fermented tomatoes. These results suggest that the succession of bacterial communities changed greatly during the fermentation process. Tomatoes fermentation is a static surface fermentation, and its main fermentation process is concentrated on the surface of fermentation broth. Since only the liquid surface is in contact with oxygen, the fermentation broth below the liquid surface isolates oxygen, which is suitable for the growth of some anaerobic or facultative anaerobes. With the progress of fermentation, the nutrient components in the fermentation broth are consumed and the $\mathrm{pH}$ continues to drop, and many acid-intolerant bacteria will disappear. After multiple selection of the environment, the microorganisms in the fermentation broth tend to be stable. The shared bacterial OTUs mainly belonged to Firmicutes and Proteobacteria at the phylum level, and Lactobacillus, Weissella, Lactococcus and Leuconostoc at the genus level.

\subsection{Analysis of bacterial community structure during natural fermentation of tomatoes}

The community succession of naturally fermented tomatoes based on phylum level classification is shown in Figure 3A. The structure of the microbial community changed constantly during the fermentation, mainly including Firmicutes, Proteobacteria, Bacteroidetes and Actinobacteria. The content of Proteobacteria was the highest (86.04\%) in G1 because most of Proteobacteria come from fresh vegetables planted in soil. In the G1-G6 phase, the content of Firmicutes increased gradually during tomato fermentation, it increased from $9.97 \%$ to $99.3 \%$. There are many probiotic groups in Firmicutes, such as Lactobacillus, Leucococcus and Enterococcus (Di Cagno et al., 2013; Rezac et al., 2018), which were present at similar levels based on the analysis of the proportions of different bacteria at the genus level. The content of Bacteroidetes and Actinobacteria decreased rapidly from $2.96 \%$ and $1.34 \%$ to $0.05 \%$ and $0.01 \%$ at the beginning of fermentation, respectively. Therefore, Firmicutes is the dominant phylum during fermentation. Because the change of microbial population in the fermentation process affects its material metabolism, which not only retains the lycopene, total sugar and other nutrients in the fermentation raw materials, but also produces a variety of physiological active substances such as total acid and polyphenols (Zhou et al., 2019), which is very beneficial to the human body. Analysis of bacterial diversity in the tomatoes fermentation process, which was performed through 16S rDNA high-throughput sequencing, showed that the bacterial diversity during the dynamic fermentation process was poor and changes over time, and dominant species become increasingly prominent.

Generally, bacteria are the main microbiota of vegetables, especially the aerobes (pseudomonads, enterobacteria and coryneforms) (Di Cagno et al., 2013). It has been found that Lactobacillus, Leuconostoc and Weissella play an important role in vegetable fermentation (Di Cagno et al., 2013; Hao \& Sun, 2020), abundance ratios differ due to regional differences and the use of different raw materials. The community succession of tomato natural fermentation based on genus-level classification is shown in Figure 3B. Gram-negative bacteria were abundant in the samples at 0-day fermentation, mainly including Pantoea, 

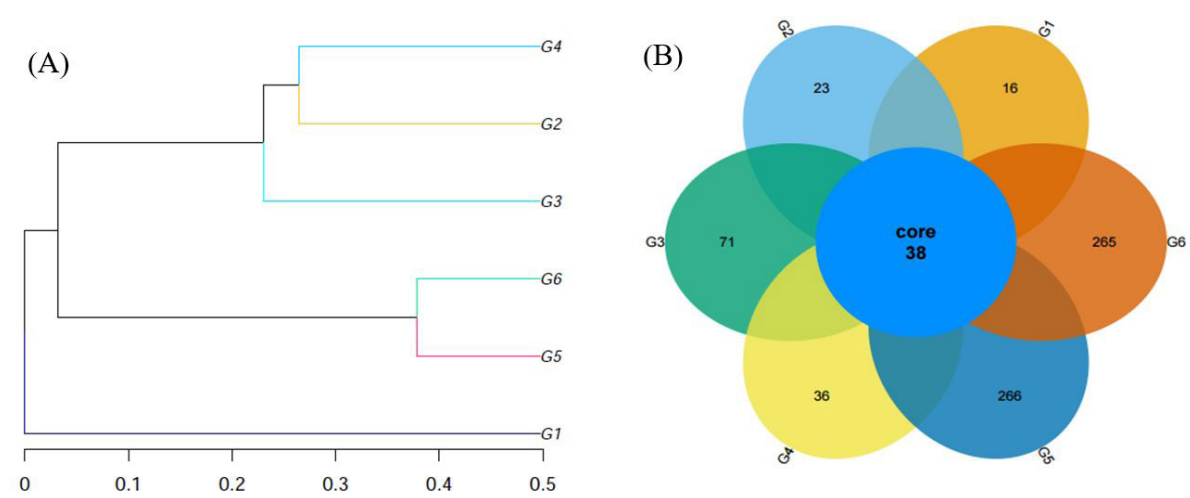

Figure 2. Bacterial abundance and diversity during natural fermentation of tomatoes. The cluster analysis of bacterial communities was shown in the panel (A), and Venn diagrams based on OTUs of bacterial sequences are shown in the panel (B).
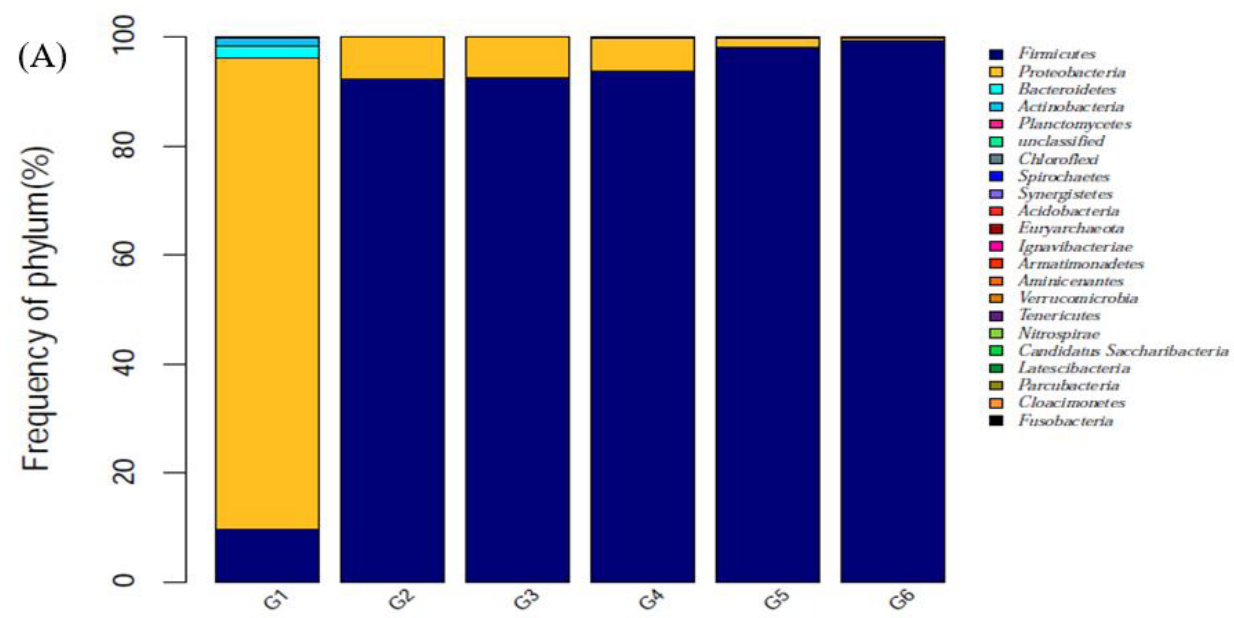

(B)
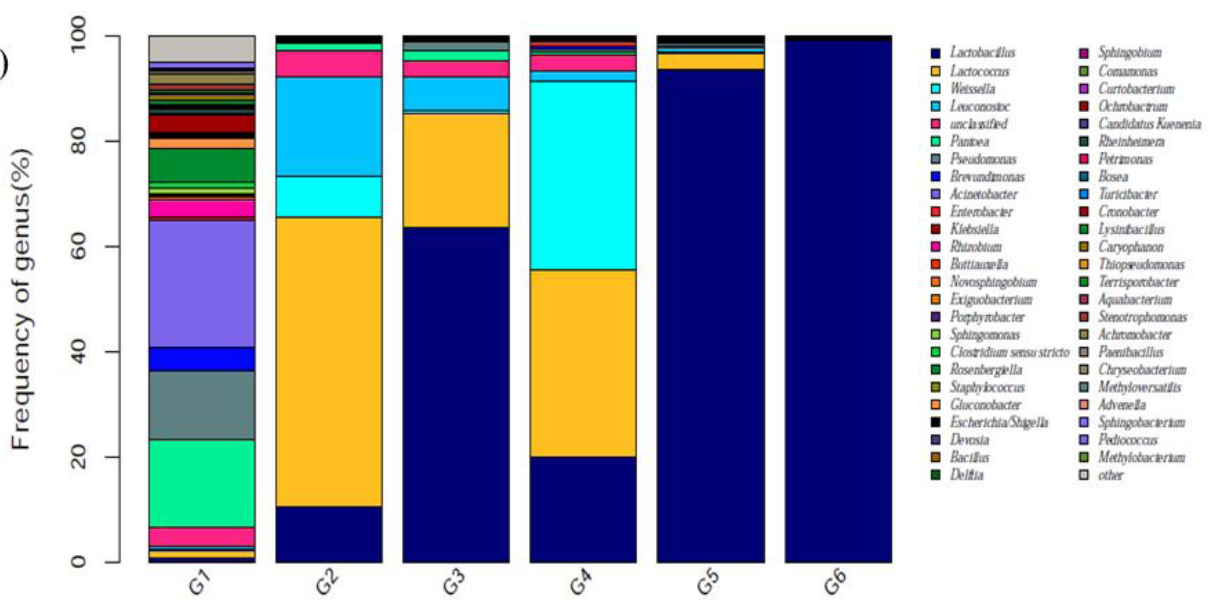

Figure 3. Relative abundance of bacteria community proportions at phylum level (A) and genus level (B).

Pseudomonas, Brevundimonas and Acinetobacter. Many members of Gram-negative bacteria are involved as pathogenic and spoilage bacteria. Thus, they are frequently considered as a hazardous source of transmissible antibiotic resistance (Wang et al. 2019). In the middle-stage of the fermentation process, the bacteria mainly included Leuconostoc, Lactococcus, Lactobacillus and Weissella, among which Lactobacillus increased continuously, the growth of these undesirable bacteria was inhibited. Weissella is primarily involved in the initial decomposition of the food substance, it is important for food flavour (Hao \& Sun, 2020), and its content decreases rapidly with prolonged fermentation. Leuconostoc is a common constituent of naturally fermented vegetables such as kimchi and can often dominate these microbial fermentations (Jung et al., 2014). Interestingly, Lactococcus was the dominant bacteria in the initial fermentation stage, which was consistent with previously reported results for kimchi (Jung et al., 2014) and apple 
cider vinegar (Song et al., 2019), but there is a certain difference in relative abundance of bacteria community proportions, the differences among the studies might be due to the diversity of vegetables, fermentation technology and climatic conditions. There was a drastic reduction in the relative abundance of Lactococcus which were detected from day 30 to day 90 of fermentation. However, Lactobacillus decreased from 20 to 30 days and then rapidly increased. It plays an important role in the glycolysis pathway and the fermentation process (Di Cagno et al., 2013; Wu et al., 2014). Therefore, Lactobacillus is the dominant bacteria in naturally fermented tomatoes, the accumulation of lactic acid made the bacterial diversity decrease in the later stages of the fermentation process. It is also a good explanation for the significant reduction of nitrite, as the acidity tends to be stable after fermentation for 30 days (Figure 1). It is speculated that the degradation of nitrite in the fermentation process is due to the denitrification of microorganisms. The relative abundance of Lactobacillus, Leuconostoc and Weissella is related to the change of nitrite concentration in the fermentation broth, which is the key to the degradation of nitrite in the fermentation process. Naturally fermented tomatoes products can not only improve the micro ecological environment in the body, moisten the intestines and defecate, but also improve its antioxidant capacity through polyphenols and organic acids produced in the fermentation process (Zhou et al., 2019), inhibit the damage of free radicals to the skin, repair damaged cells and delay aging.

\subsection{Cluster analysis during natural fermentation of tomatoes}

Heat map analysis was performed to compare the differences and similarities in the bacterial community structure of tomatoes during fermentation as shown in Figure 4. The microbiome profiles of the fermented food were somewhat surprising. At the genus level, there was a large gap between G1 and the other groups through the comparison of color gradient and similarity, and G2-G5 group clustered closely. This shows that the microbial diversity decreases with the maturity of naturally fermented tomato, and the species richness becomes more and more similar. G1 had the highest diversity index based on alpha diversity, the simpson index and the shannon index, containing mainly Pseudomonas, Pantoea, Brevundimonas, Acinetobacter, Rhizobium, Sphingomonas; Proteobacteria, Firmicutes and Bacteroidetes, which accounted for $86.04 \%, 9.97 \%$ and $2.96 \%$ of the community based on phylum-level classification, respectively. The fermentation duration also affected the microbial community compositions significantly. At the initial stage of fermentation, Lactococcus, Lactobacillus, Weissella and Leuconostoc increased significantly, resulting in a decrease of $\mathrm{pH}$. Firmicutes increased from $9.97 \%$ to $92.45 \%$ during the first 20 days, but there were still

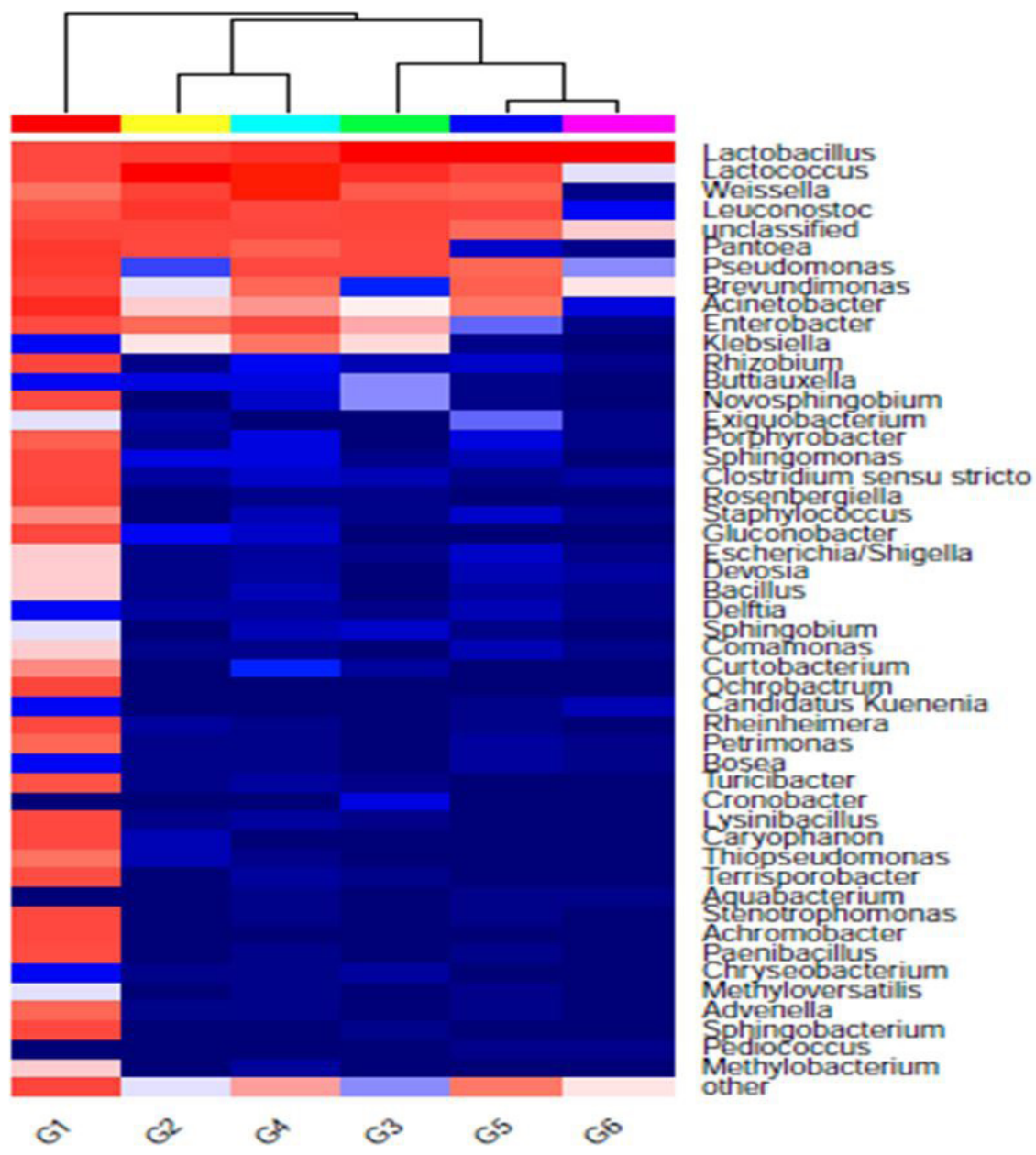

Figure 4. Heat map from clustering during natural fermentation of tomatoes. 
Proteobacteria present which increased the nitrite content in the fermentation broth. Interestingly, Lactococcus was dominant in the G2 stage, while Lactobacillus and Weissella were dominant in the G3 and G4 stage, separately. The microbial diversity decreased significantly in the later stages of the tomato fermentation, mainly due to the increase in Firmicutes, accounting for $99.3 \%$ of the bacteria present. This confirms the results of the genuslevel beta-diversity analysis (Figure 2). These results indicate that core functional microorganisms becoming dominant microorganisms can conducive to improve the hygienic quality of fermented tomatoes. The majority of the strains were assigned to Leu.mesenteroides and Lb. casei species have been reported to dominate green tomatoes fermentations (Paramithiotis et al., 2012). During fermentation, the physic-chemical parameters inevitably change, mainly due to microbial metabolism, affecting in turns the development of the micro-ecosystem.

\section{Conclusion}

This study revealed for the first time the dynamic succession of the bacterial community during natural fermentation of tomatoes by high-throughput sequencing. It showed that the production of citric acid, malic acid and lactic acid in the broth gradually increased with the tomatoes fermentation, resulting in an increased total acid content and a decrease in total sugar content. Analysis of the microbial diversity in the tomatoes fermentation process, which performed through 16S rDNA high-throughput sequencing, showed that the bacterial diversity of tomatoes during the dynamic natural fermentation process changes over time. Pantoea, Pseudomonas, Brevundimonas and Acinetobacter were the predominant bacteria in the early stage of tomatoes fermentation. Leuconostoc, Lactococcus, Lactobacillus and Weissella were the predominant bacteria at the middle stage of fermentation, among which Lactobacillus increased continuously, growing rapidly to reach an abundance of $98.99 \%$ by the end of the fermentation. Lactobacillus metabolises lactic acid and other organic acids, reducing the $\mathrm{pH}$. The accumulation of lactic acid decreased the bacterial diversity in the later stages of the fermentation process. These changes in the bacterial community are also a good explanation for the significant reduction of nitrite, which occurred when the acidity stabilised after fermentation for 30 days. The natural fermentation induced drastic changes in the microbiology and metabolite profiles of the tomatoes. We think that a variety of microorganisms synergistically form flavour of fermented products. In conclusion, our present study has systematically investigated the microbial diversity during the dynamic fermentation of tomatoes, and provided guidance for the purification and application of functional bacteria and the industrial promotion of fermented fruits and vegetables.

\section{Acknowledgements}

This work was financially supported by Supported by National Natural Science Foundation of China (32060536), Discipline and Master's Site Construction Project of Guiyang University by Guiyang City Financial Support Guiyang University [SY-2020], Youth Science and Technology Talent Growth Project of Education Department of Guizhou Province (KY[2018]294).

\section{References}

Alarcón-Flores, M. I., Romero-González, R., Martínez Vidal, J. L., \& Garrido Frenich, A. (2015). Multiclass determination of phenolic compounds in different varieties of tomato and lettuce by ultra high performance liquid chromatography coupled to tandem mass spectrometry. International Journal of Food Properties, 19(3), 494507. http://dx.doi.org/10.1080/10942912.2014.978010.

Aldrete-Tapia, A., Escobar-Ramírez, M. C., Tamplin, M. L., \& Hernández-Iturriaga, M. (2014). High-throughput sequencing of microbial communities in poro cheese, an artisanal mexican cheese. Food Microbiology, 44, 136-141. http://dx.doi.org/10.1016/j. fm.2014.05.022. PMid:25084655.

Anal, A. (2019). Quality ingredients and safety concerns for traditional fermented foods and beverages from Asia: a review. Fermentation, 5(1), 8. http://dx.doi.org/10.3390/fermentation5010008.

Berbegal, C., Borruso, L., Fragasso, M., Tufariello, M., Russo, P., Brusetti, L., Spano, G., \& Capozzi, V. (2019). A metagenomic-based approach for the characterization of bacterial diversity associated with spontaneous malolactic fermentations in wine. International Journal of Molecular Sciences, 20(16), 3980. http://dx.doi.org/10.3390/ ijms20163980. PMid:31443334.

Carraro, L., Maifreni, M., Bartolomeoli, I., Martino, M. E., Novelli, E., Frigo, F., Marino, M., \& Cardazzo, B. (2011). Comparison of culture-dependent and -independent methods for bacterial community monitoring during Montasio cheese manufacturing. Research in Microbiology, 162(3), 231-239. http://dx.doi.org/10.1016/j. resmic.2011.01.002. PMid:21262359.

David, L. A., Maurice, C. F., Carmody, R. N., Gootenberg, D. B., Button, J. E., Wolfe, B. E., Ling, A. V., Devlin, A. S., Varma, Y., Fischbach, M. A., Biddinger, S. B., Dutton, R. J., \& Turnbaugh, P. J. (2014). Diet rapidly and reproducibly alters the human gut microbiome. Nature, 505(7484), 559-563. http://dx.doi.org/10.1038/nature12820. PMid:24336217.

Di Cagno, R. D., Coda, R., Angelis, M. D., \& Gobbetti, M. (2013). Exploitation of vegetables and fruits through lactic acid fermentation. Food Microbiology, 33(1), 1-10. http://dx.doi.org/10.1016/j. fm.2012.09.003. PMid:23122495.

Dimidi, E., Cox, S. R., Rossi, M., \& Whelan, K. (2019). Fermented Foods: Definitions and characteristics, impact on the gut microbiota and effects on gastrointestinal health and disease. Nutrients, 11(8), 1806. http://dx.doi.org/10.3390/nu11081806. PMid:31387262.

Din, A., Amir, R. M., Ameer, K., Ahmad, A., Nadeem, M., Chughtai, M. F. J., Khaliq, A., Ahsan, S., Khan, M. I., Riaz, A., \& Kausar, R. (2020). Assessment of quality attributes of tomato sauce supplemented with moringa root. Food Science and Technology, 40(4), 1014-1020. http:// dx.doi.org/10.1590/fst.26719.

Elizaquível, P., Pérez-Cataluña, A., Yépez, A., Aristimuño, C., Jiménez, E., Cocconcelli, P. S., Vignolo, G., \& Aznar, R. (2015). Pyrosequencing vs. culture-dependent approaches to analyze lactic acid bacteria associated to chicha, a traditional maize-based fermented beverage from northwestern argentina. International Journal of Food Microbiology, 198, 9-18. http:// dx.doi.org/10.1016/j.ijfoodmicro.2014.12.027. PMid:25584777.

Gänzle, M. G. (2015). Lactic metabolism revisited: metabolism of lactic acid bacteria in food fermentations and food spoilage. Current Opinion in Food Science, 2, 106-117. http://dx.doi.org/10.1016/j. cofs.2015.03.001.

Hao, Y., \& Sun, B. (2020). Analysis of bacterial diversity and biogenic amines content during fermentation of farmhouse sauce from Northeast China. Food Control, 108, 106861. http://dx.doi.org/10.1016/j. foodcont.2019.106861. 
He, F. J., Nowson, C. A., Lucas, M., \& MacGregor, G. A. (2007). Increased consumption of fruit and vegetables is related to a reduced risk of coronary heart disease: metaanalysis of cohort studies. Journal of Human Hypertension, 21(9), 717-728. http://dx.doi.org/10.1038/ sj.jhh.1002212. PMid:17443205.

Hur, S. J., Lee, S. Y., Kim, Y. C., Choi, I., \& Kim, G. B. (2014). Effect of fermentation on the antioxidant activity in plant-based foods. Food Chemistry, 160(10), 346-356. http://dx.doi.org/10.1016/j. foodchem.2014.03.112. PMid:24799248.

Jayabalan, R., Subathradevi, P., Marimuthu, S., Sathishkumar, M., \& Swaminathan, K. (2008). Changes in free-radical scavenging ability of kombucha tea during fermentation. Food Chemistry, 109(1), 227-234. http://dx.doi.org/10.1016/j.foodchem.2007.12.037. PMid:26054285.

Jung, J. Y., Lee, S. H., \& Jeon, C. O. (2014). Microbial community dynamics during fermentation of doenjang-meju, traditional korean fermented soybean. International Journal of Food Microbiology, 185, 112-120. http://dx.doi.org/10.1016/j.ijfoodmicro.2014.06.003. PMid:24960292.

Kang, J. Y., Hong, J., Gao, Y., Yang, Y., Chen, M., Yi, X. X., \& Gao, X. Z. (2019). Analysis of bacterial diversity during fermentation of naturally ermented vegetables in Shanxi. Food Science, 40(10), 106-111.

Liu, H. F., Wu, B. H., Fan, P. G., Li, L. S., \& Li, L.-S. (2006). Sugar and acid concentrations in 98 grape cultivars analyzed by principal component analysis. Journal of the Science of Food and Agriculture, 86(10), 1526-1536. http://dx.doi.org/10.1002/jsfa.2541.

Lozupone, C., Hamady, M., \& Knight, R. (2006). Unifracan online tool for comparing microbial community diversity in a phylogenetic context. BMC Bioinformatics, 7(1), 371-380. http://dx.doi.org/10.1186/14712105-7-371. PMid:16893466.

Murphy, R. P. (1958). A method for the extraction of plant samples and the determination of total soluble carbohydrates. Journal of the Science of Food and Agriculture, 9(11), 714-717. http://dx.doi. org/10.1002/jsfa.2740091104.

Ono, H., Nishio, S., Tsurii, J., Kawamoto, T., Sonomoto, K., \& Nakayama, J. (2014). Monitoring of the microbiota profile in nukadoko, a naturally fermented rice bran bed for pickling vegetables. Journal of Bioscience and Bioengineering, 118(5), 520-525. http://dx.doi. org/10.1016/j.jbiosc.2014.04.017. PMid:24906947.

Opara, U. L., Al-Ani, M. R., \& Al-Rahbi, N. M. (2012). Effect of fruit ripening stage on physico-chemical properties, nutritional composition and antioxidant components of tomato (Lycopersicum esculentum) cultivars. Food and Bioprocess Technology, 5(8), 3236-3243. http:// dx.doi.org/10.1007/s11947-011-0693-5.

Paramithiotis, S., Doulgeraki, A. I., Tsilikidis, I., Nychas, G. J. E., \& Drosinos, E. H. (2012). Fate of Listeria monocytogenes and Salmonella Typhimurium during spontaneous cauliflower fermentation. Food Control, 27(1), 178-183. http://dx.doi.org/10.1016/j.foodcont.2012.03.022.

Paramithiotis, S., Kouretas, K., \& Drosinos, E. H. (2014). Effect of ripening stage on the development of the microbial community during spontaneous fermentation of green tomatoes. Journal of the Science of Food and Agriculture, 94(8), 1600-1606. http://dx.doi. org/10.1002/jsfa.6464. PMid:24284907.

Pellicanò, T. M., Sicari, V., Loizzo, M. R., Leporini, M., Falco, T., \& Poiana, M. (2020). Optimizing the supercritical fluid extraction process of bioactive compounds from processed tomato skin byproducts. Food Science and Technology, 40(3), 692-697. http://dx.doi. org/10.1590/fst.16619.

Połka, J., Rebecchi, A., Pisacane, V., Morelli, L., \& Puglisi, E. (2015). Bacterial diversity in typical Italian salami at different ripening stages as revealed by high-throughput sequencing of $16 \mathrm{~S}$ rRNA amplicons. Food Microbiology, 46, 342-356. http://dx.doi.org/10.1016/j. fm.2014.08.023. PMid:25475305.
Raghuvanshi, R., Grayson, A. G., Schena, I., Amanze, O., Suwintono, K., \& Quinn, R. A. (2019). Microbial transformations of organically fermented Foods. Metabolites, 9(8), 165-179. http://dx.doi.org/10.3390/ metabo9080165. PMid:31405168.

Rezac, S., Kok, C. R., Heermann, M., \& Hutkins, R. (2018). Fermented foods as a dietary source of live organisms. Frontiers in Microbiology, 9, 1785. http://dx.doi.org/10.3389/fmicb.2018.01785. PMid:30197628.

Ruiz-Moyano, S., Martínn, A., Benito, M. J., Hernández, A., Casquete, R., \& Guia Córdoba, M. (2011). Application of Lactobacillus fermentum HL57 and Pediococcus acidilactici SP979 as potential probiotics in the manufacture of traditional Iberian dry-fermented sausages. Food Microbiology, 28(5), 839-847. http://dx.doi.org/10.1016/j. fm.2011.01.006. PMid:21569925.

Scherer, R., Rybka, A. C. P., Ballus, C. A., Meinhart, A. D., Teixeira, J. Fo., \& Godoy, H. T. (2012). Validation of a hplc method for simultaneous determination of main organic acids in fruits and juices. Food Chemistry, 135(1), 150-154. http://dx.doi.org/10.1016/j. foodchem.2012.03.111.

Shukla, S., Choi, T. B., Park, H. K., Kim, M., Lee, I. K., \& Kim, J. K. (2010). Determination of non-volatile and volatile organic acids in korean traditional fermented soybean paste (Doenjang). Food and Chemical Toxicology, 48(8-9), 2005-2010. http://dx.doi.org/10.1016/j. fct.2010.04.034. PMid:20434502.

Siddiqui, M. W., Chakraborty, I., Homa, F., \& Dhua, R. S. (2016). Bioactive compounds and antioxidant capacity in dark green, old gold crimson, ripening inhibitor, and normal tomatoes. International Journal of Food Properties, 19(3), 688-699. http://dx.doi.org/10.108 0/10942912.2015.1038563.

Song, J., Zhang, J. H., Kang, S. J., Zhang, H. Y., Yuan, J., Zeng, C. Z., Zhang, F., \& Huang, Y. L. (2019). Analysis of microbial diversity in apple vinegar fermentation process through $16 \mathrm{~s}$ rdna sequencing. Food Science \& Nutrition, 7(4), 1230-1238. http://dx.doi.org/10.1002/ fsn3.944. PMid:31024696.

Tamang, J. P., Watanabe, K., \& Holzapfel, W. H. (2016). Review: diversity of microorganisms in global fermented foods and beverages. Frontiers in Microbiology, 7, 377. http://dx.doi.org/10.3389/fmicb.2016.00377. PMid:27047484.

Topalovic, A., \& Mikulic-Petkovsek, M. (2010). Changes in sugars, organic acids and phenolics of grape berries of cultivar cardinal during ripening. Journal of Food Agriculture and Environment, 8(3), 223-227.

Vázquez-Baeza, Y., Pirrung, M., Gonzalez, A., \& Knight, R. (2013). EMPeror: a tool for visualizing high-throughput microbial community data. GigaScience, 2(1), 16. http://dx.doi.org/10.1186/2047-217X-2-16. PMid:24280061.

Wang, X. H., Ren, H. Y., Liu, D. Y., Zhu, W. Y., \& Wang, W. (2013). Effects of inoculating lactobacillus sakei starter culture on the microbiological quality and nitrite depletion of chinese fermented sausages. Food Control, 32(2), 591-596. http://dx.doi.org/10.1016/j. foodcont.2013.01.050.

Wang, X. H., Wang, S. H., \& Zhao, H. (2019). Unraveling microbial community diversity and succession of chinese sichuan sausages during spontaneous fermentation by high-throughput sequencing. Journal of Food Science and Technology-Mysore, 56(7), 3254. http:// dx.doi.org/10.1007/s13197-019-03781-y. PMid:31274892.

Wu, R. N., Yu, M. L., Meng, L. S., Xu, X., \& Wu, J. R. (2014). PCR-DGGE analysis of the microbial diversity in naturally fermented suan-cai from northeast China. Modern Food Science and Technology, 30(10), 8-12.

Zhou, X. L., Zhang, D., Zhu, G. X., \& Kong, Y. Q. (2019). Study on the changes of antioxidants and their activities of tomatoes during the fermentation process. IOP Conference Series: Earth Environment Science, 332, 032028. http://dx.doi.org/10.1088/1755-1315/332/3/032028. 